\title{
SISTEMÁTICA PENAL E LIMITES DAS PROPOSTAS FUNCIONALISTAS (PONDERAÇÕES SOBRE GARANTIAS, CIDADANIA E DIREITOS HUMANOS)
}

Felipe Augusto Forte de Negreiros Deodato

Doutor e Mestre em Direito Penal pela Universidade de Coimbra, Portugal. Professor de Direito do Centro Universitário de João Pessoa - UNIPÊ e da Universidade Federal da Paraíba - UFPB. Advogado.

Rômulo Rhemo Palitot Braga Doutor e Mestre em Direito Penal pela Universitat de València, Espanha. Professor de Direito do Centro Universitário de João Pessoa - UNIPÊ e da Universidade Federal da Paraíba. Advogado.

\section{Resumo}

Fazer uma crítica ao funcionalismo significa olhar para a própria história da edificação dos sistemas penais. É assim que se vê que é o rigor da análise algo que se impóe quando temos um sistema como uma ferramenta de trabalho. É a crítica ao que hoje se coloca em termos jurídico-penais que se enxerga o quanto o estudo do direito penal deve ser cada vez mais preciso e também mais próximo da ideia de dignidade humana. Também irá ser construída uma crítica aos dois movimentos que mudaram a face da primeira sistemática, desenhada ainda nos oitocentos, o que nos permitirá enxergar com mais precisão o que pode, ou mesmo deve, ser alterado. Não se pode deixar de enaltecer o normativismo, sobretudo o que recebeu o reforço indelével dos cultores da ciência penal da segunda metade do século passado.

\section{Palavras-chave}

Dogmática; Sistemas; Política Criminal.

\begin{abstract}
Make a critique of functionalism means looking at the history of the construction of the penal systems. It is observed that the rigor of analysis is something that is imposed when we have a system as a tool work. It is essential for that what now arises in legal and criminal terms sees as the study of criminal law should be increasingly precise and also
\end{abstract}


closer to the idea of human dignity. It will also be built a criticism for the two doctrines that have changed the face of the first systematic, designed in the nineteenth, which will allow us to see more accurately what can, or even should, be changed. One cannot help but praise the normativism, especially what received the indelible strengthening of the cultivators of criminal science of the past half century.

\section{Key words}

Dogmatic; Systems; Criminal Policy.

\section{Introdução}

É muito comum se ouvir que a dogmática é uma barreira intransponível do direito penal. Contudo, as novas formas de relaçôes da sociedade contemporânea dão origem a quadros diversos, de onde o nosso tempo não se mostra com uma única feição, um único rosto, mas com múltiplas feiçóes.

E isso exige uma mudança de compreensão tanto da dogmática como do debate que termina nas propostas legislativas que regem o cotidiano. Vem daí os questionamentos, sobre o ponto em que se é possível relativizar as amarras da dogmática; introduzir-se, ainda mais, ideias de teor normativista e funcionalista no sistema lógico, dogmático e dedutivo, edificado ao longo desses últimos dois séculos.

A realidade presente deixa estreme de dúvidas que o grau de complexidade das relaçôes sociais inaugura não só novos espaços de interesse jurídico-penal, mas também um alto nível de problematicidade que póe em xeque os instrumentos até então desenvolvidos pela penalística. Demonstrar em que medida a maior mudança sofrida pelo nosso sistema teórico deu frutos é o primeiro enfoque dessa pesquisa.

Através da clara percepção do que se propôs no século XIX e do que ocorreu no começo do século XX é que se poderá enfrentar a série de questóes emergentes que esse tempo de vertigem sugere. Manter-se com firmeza as garantias e o respeito ao cidadão que a penalística sempre almejou. E será esse o outro enfoque desse estudo. Far-se-á uma abordagem sobre como as propostas funcionalistas mais atuais podem atingir tais garantias.

\section{Franz Von Liszt: Algumas Palavras sobre o Pai do Causalismo}

De logo, trace-se breves linhas sobre a pessoa deste importante penalista dos oitocentos. Olhemos que Liszt (1851-1919) nasceu em Viena, Áustria, e morreu em Berlim, Alemanha (ZAFFARONI; PIERANGELI, 1999, pp. 30 e ss.). Sua longevidade permitiu que escrevesse um conjunto ímpar de obras jurídicas. Fez seus primeiros estudos 
de direito na Universidade de Viena, entre os anos de 1869 e 1873 . Destacou-se como doutrinador quando começou a ensinar nas seguintes universidades: Giessen, nos anos de 1879 e 1882; Marburgo, nos anos de 1882 e 1889; Halle, no ano de 1889, e Berlim, entre 1889 e 1916. Foi nesse último período que escreveu o seu manual de direito penal. Nele, formulou a sistemática da teoria do crime e o seu famoso programa de Marburgo, base da teoria das penas (ZAFFARONI; PIERANGELI, ${ }^{1999}$, ${ }^{\text {pp. } 30 \text { e ss.). }}$

Além de sua notável atividade acadêmica, em 1889, Liszt fundou a União Internacional de Direito Penal, junto com os professores Hamel e Prins. Em 1924, essa organização se transformou na Associação Internacional de Direito Penal. E antes disso, em 1881, já havia criado a mais atual e importante revista especializada em direito penal, a Zeitschrift für die gesamte Strafrechtwissenchaft. Uma revista que ainda hoje é publicada trimestralmente pela editora alemã Walter de Gruyter, com sede em Berlim e Nova York.

$\mathrm{Na}$ verdade, foi através de uma extensa atividade acadêmica que Liszt criou a primeira forma de ensinar ou doutrinar o futuro exegeta, consagrada no sistema causalista ${ }^{1}$. Esse sistema foi de fundamental importância para a formação da jurisprudência do Tribunal do Reich, exercendo grande influência em todos os países que seguem a dogmática alemá. Cite-se: os países da Europa continental, África, América Latina, Japão, China etc.

Para além disso, a escola causalista, também chamada de naturalista, fixou as bases para o Código Penal alemão de 1871, por meio de uma concepção que funcionou como um verdadeiro contraponto às teses de importantes professores que defendiam um sistema clássico, tais quais Birkmeyer e Binding (FREITAS, 2002, pp. 17 e ss.; BRANDÃo, 2001, pp. 09 e ss.). Mas, qual foi o ponto central da concepção do sistema causalista? Com efeito, passemos agora a estabelecer, com rigor metodológico, o que norteava as ideias de Liszt.

\section{Os Fundamentos do Século XIX: Ciência é o Empiricamente Demonstrável}

Neste ponto, faz-se importante comentar, mesmo que sucintamente, o real significado da essência objetiva tão intrinsecamente ligada ao outro termo que também dá nome à escola causalista: "naturalista". Olhar que é corriqueiro ver-se certa confusão entre o fato de Liszt ser um positivista e se falar de seu trabalho acadêmico como uma expressão literária de uma corrente do pensamento "naturalista".

Ora, há de se atentar para o fato de que a palavra "naturalista" aqui não significa o mesmo que naturalismo ou, mais especificamente, o mesmo que jusnaturalismo. $\mathrm{Na}$

1 Conforme esclarecem Maurach e Zipf, a importância de Liszt chegou até os nossos dias. E isto se dá não pela vida longeva do referido professor, que viveu até os fins da segunda década do século XX, mas porque foi o primeiro autor a explicar, de uma maneira sistemática, o crime e a pena. (MAURACH; ZIPF, 1994. pp. 97 e ss.) 
realidade, significa que Liszt construiu todo o sistema de palavras, desde os mais simples aos mais complexos conceitos e classificaçôes (legítima defesa, culpa, dolo etc.), através de uma ótica que fosse ilustrada por meio de uma percepção sensorial.

A esse respeito, transcreve-se a lição de Juarez Tavares 2000, pp. 17 e ss.; 2003, pp. 21 e ss.): "Em linhas gerais, podemos caracterizar esse sistema pelo fato de que, nele, a ação humana é tomada essencialmente como processo causal de um resultado".

De um modo ainda mais claro, olhe-se que para Liszt, toda a palavra que viesse a integrar esse sistema ou conjunto deveria ser pensada como algo que expressasse a ordem natural ou física das coisas ${ }^{2}$.

Segundo acrescenta Figueiredo Dias (2004, pp. 225 e ss.), esta era uma maneira de pensar que "tinha como ideal a exatidão científica própria das ciências da natureza e a ele deveria incondicionalmente submeter-se; de sorte que, do mesmo modo, o sistema do facto punível haveria de ser apenas constituído por realidades mensuráveis e empiricamente comprováveis".

De acordo com o que anota Figueiredo Dias, ligava-se a faticidade do mundo exterior aos processos psíquicos internos.

$\mathrm{Na}$ verdade, foi a partir dessa base que Liszt fez, por exemplo, a classificação dos delitos.

Ora, veja-se que, quando se pretende classificar qualquer coisa, é comum dar-se realce a certas características, a fim de distingui-la, particularizando o que está sendo observado.

Tomem-se como paradigma os seres humanos. Quando se deseja conhecer mais detalhadamente as pessoas, elas são observadas sob algum aspecto, a altura, o peso. Assim também Liszt procedeu na análise do crime (GOMES, 2010, pp. 100 e ss.).

Dito de outro modo, os alemães, desde cedo, verificaram que seria impossível decorar todos os tipos de crimes existentes, pois eles iam surgindo de acordo com o momento presente.

Daí se preocuparem em identificar as características que os vários crimes poderiam possuir. Quanto ao resultado, por exemplo, Liszt observou que os crimes seriam materiais e de mera conduta.

Registre-se que ele não previu o crime formal, que é uma conduta, cuja ofensa não é percebida sensorialmente como um crime, mas que a norma assim a classifica ${ }^{3}$.

2 Como se disse, sequer os fatores de consciência deveriam ser considerados.

3 Isso fica claro quando se olha para o crime de corrupção ativa, previsto no art. 317, do Código Penal brasileiro. Esse crime se caracteriza por pedir um servidor público um benefício, em troca de um serviço 
Segundo sua concepção, os crimes materiais eram aqueles cujo resultado não coincidia com a conduta.

Ou seja, o resultado náo existiria necessariamente depois da conduta. $\mathrm{O}$ crime de homicídio é um exemplo. Não é pelo fato de se atirar em alguém que este obrigatoriamente morrerá.

Com efeito, tal conclusão não acontece através do que expressa uma norma que teria de ser decorada. Essa é uma conclusão da própria percepção, até sensorial, a que se chega quando se pensa mentalmente, que, no homicídio, naturalmente, a conduta não conduzirá necessariamente ao resultado morte. Ao receber um tiro, a pessoa pode morrer, mas não necessariamente e sempre. Ela pode ir para um hospital e se salvar.

Era um olhar fechado. E tudo isto tinha uma razão de ser. Uma razão presa aos fundamentos do século XIX ${ }^{4}$. Um universo em que tudo se olhava através da mecânica newtoniana. Isto porque, àquela época, imaginava-se que só era científico o que transmitia uma ideia de exatidão. Só tinha validade o que podia ser demonstrado em um contexto físico. Nesse ambiente, era natural que as ciências do espírito sofressem preconceitos, fossem vistas como algo menor.

Foi justamente com o objetivo de minimizar esse problema que Liszt criou esse sistema (tal qual uma tabela periódica) em que cada palavra que o integre transmitisse a ideia de algo concreto. Reitere-se que para ele só podia integrar o sistema a palavra ou o que naturalmente concretizasse nas mentes das pessoas uma situação concreta ou que fosse vista como algo lógico (natural).

Foi a partir desse pressuposto que se passou a entender o homicídio como um crime classificado como material, pois, como se disse, mentalmente e não de outro modo, vê-se que há uma separação entre a conduta de quem atira e o resultado morte.

Tal exercício de reflexão é, para Liszt, o que caracterizava a ciência do direito penal como algo exato. É, em síntese, o que expressa o próprio sentido de ciência. Esse fundamento, ao seu entender, tornava científico o trabalho que ele realizava. Daí náo se confundir o termo "naturalista" com o movimento filosófico e artístico chamado de naturalismo. Liszt era positivista, na medida em que tinha a lei por base. Apenas defendia que o direito penal, transmitido pela doutrina, devia ser fundado no mundo real, isto é, no mundo regido pela natureza das coisas.

que por lei deve realizar gratuitamente. Ora, a ofensa se consuma no momento em que dito servidor receber o dinheiro. Isso é o que se percebe, ao se deter sobre esse caso concreto. Todavia, a norma dispóe no referido dispositivo, que, independentemente do recebimento de qualquer benefício, o crime já se consuma, desde o instante em que o funcionário o pede.

4 Conforme assinala Figueiredo Dias (2004. pp. 225 e ss.), a visão de Liszt estava assentada em uma concepção do jurídico influenciada pela chamada Escola Moderna e pelo "naturalismo positivista" que caracterizou o "monismo" científico próprio de todo o pensamento da segunda metade do século XIX. 
Justamente por isso, para ele, o direito penal concretizava uma ciência, nos moldes de uma ciência da natureza. Um ideário que, como dito, foi alterado no começo do século XX. Senão vejamos, passemos agora a comentar as linhas que mudaram o sistema edificado por Liszt.

\section{0 que foi o Neokantismo: Introdução do Normativismo como Primeira Fle- xibilização do Sistema Penal Lógico, Dogmático e Dedutivo}

Olhemos que no pensamento causalista o crime tinha dois requisitos: fato típico e culpabilidade. O primeiro resguardava o aspecto objetivo ou legal do delito ou mesmo a sua imputatio facti, como se falava ${ }^{5}$. O segundo referia-se ao aspecto pessoal do delito ou à chamada imputatio juris ${ }^{6}$, composta pelo dolo ou culpa. Com outras palavras, os requisitos do crime eram postos como o que naturalmente se contextualizava nas mentes das pessoas. A partir de uma relação natural: culpabilidade $=$ culpa + dolo $^{7}$.

Tal modo de pensar perdurou por quase cem anos, mas, com o advento da teoria da relatividade, no século XX, esse modelo se transformou ${ }^{8}$. É que a partir da teoria da relatividade alguns autores começaram a defender as teses que, duzentos anos atrás, foram propostas por Kant. Argumentavam que, para se chegar à justiça, não havia como se basear sempre em algo que fisicamente se imaginava ou que empiricamente se construía nas mentes das pessoas. Dever-se-ia, portanto, contextualizar e construir os conceitos e os elementos teóricos (ou os dogmas integrantes do sistema penal), a partir também de um modelo metafísico. Como se disse, para Liszt, era imprescindível que toda palavra posta no citado sistema dogmático fosse realmente fácil de estabelecer na nossa mente.

Todavia, em que pese o gênio de Liszt, no começo do século XX, viu-se que era o momento de mudar. Segundo Figueiredo Dias, a maneira de enxergar a realidade que

5 De acordo com Juarez Tavares (2000, pp. 17 e ss.; 2003, pp. 21 e ss.), era uma etapa caracterizada pela exclusão do dolo e de tudo o que fosse subjetivo. Tal rejeição tinha sua razão de ser, "tendo em vista que o direito penal se organiza no sentido de evitar, preliminarmente, que efeitos danosos ou perigosos (resultados indesejáveis) de uma atividade se verifiquem concretamente", independentemente da intenção do agente.

6 Na segunda etapa, tudo ficaria adstrito à condição pessoal de responsabilidade, fundada na condição subjetiva entre o agente e o fato.

7 Seguia-se, segundo os ensinamentos de Figueiredo Dias, "uma bipartição do conceito do crime que agrupasse os seus elementos constitutivos na vertente objectiva (a acção típica e ilícita) e na vertente subjectiva (a acçấo culposa). Essa concepçáo ainda hoje está muito viva, por exemplo, na doutrina francesa dominante, que se limita, em regra, a distinguir no conceito de crime l'element material e l'element moral de l'infraction". (DIAS, 2004, pp. 225 e ss.).

8 Alguns autores, como Juarez Tavares (2003, pp. 21 e ss.), lembram também que doutrinas, como a francesa, ainda conservam remanescentes dessa postura, "dividindo o delito em três partes integrantes: o elemento legal, o elemento material e o elemento moral, de modo que os dois primeiros constituiriam o injusto, e o último a culpabilidade". 
Liszt ensinou restringia, de forma não admissível, a base de toda a construção desenvolvida para o direito penal ${ }^{9}$. Para autores, como Frank (2004, pp. 30 e ss.), realmente, tinha razão Kant quando ensinava que nem tudo deveria seguir uma ordem natural.

Às vezes, por exemplo, tinha-se que enxergar uma parede de cor preta como sendo de cor branca, porque simplesmente era melhor que fosse vista assim. Ao se transferir isso para o campo do direito, pode-se afirmar: É melhor fazer uma norma que leve a enxergar algo que divirja do que os sentidos expressam.

Os autores que propuseram isso foram chamados de neokantistas ou normativistas. Autores que apesar de não terem modificado a fundo o sistema causalista, iniciaram um movimento que terminou por permitir a Welzel a edificação do que ele chamou de sistema finalista ${ }^{10}$.

De fato, foi a partir das ideias desse grupo de jovens autores que se passou a entender que o sistema penal deveria observar duas lógicas: uma fundada no contexto natural e outra no contexto formal. O contexto natural seria o elemento verdadeiro ou óbvio (expresso pelos nossos sentidos, como a visão), enquanto o formal seria um real construído. Uma abstração que permitiria a fuga da realidade, com fundamento nessa ideia de que, assim refletindo e decidindo, os indivíduos seriam mais justos ${ }^{11}$.

Repita-se, é como se olhassem que, muito embora uma parede tivesse a cor preta (materialmente falando), às vezes era importante admitir outra cor. E esta cor diversa da realidade deveria ser estabelecida pela norma. Em síntese, foi a partir desse raciocínio que teve início o movimento que tanto quanto os seus integrantes se chamou de normativismo ou neokantismo (ROXIN, 2000, pp. 30 e ss.). Nele, a razão não seria determinada por ter de ser presa ao "ser" (ou à natureza em si) das coisas, mas por um "dever-ser"12.

9 Para Figueiredo Dias (2004, pp. 226 e ss.), isto "conduziria a afirmaçốes tão estranhas à realidade da vida como a de que a acção, no crime de injúria, consistiria na emissão de ondas sonoras dirigidas ao aparelho auditivo do receptor; ou que, na omissão, o que relevaria como acçấo seria a acção precedente (a mãe seria punida não por ter deixado morrer o seu bebé a fome, mas por, em vez de o amamentar, ter ido passar um fim de semana no campo)".

10 Transcrevem-se, a propósito, as liçôes de Silva Sánchez (1992, p. 56): "O neokantismo substitui o método puramente jurídico-formal do positivismo, introduzindo consideraçôes axiológicas e materiais".

11 Segundo Figueiredo Dias (2004, p. 227), no fundo, o pensamento de Liszt foi abandonado no preciso momento em que se pôde compreender que não mais eram defensáveis os fundamentos ideológicos e filosóficos sobre os quais aquele pensamento se assentava. "É verdade que a ele coube o mérito indeclinável de, pela primeira vez, ter sido erigido todo um sistema do crime assente numa rigorosa metódica categorial-classificatória, dotado de uma notabilíssima clareza e simplicidade”.

12 Quando se fala no "ser" das coisas, quer-se falar na realidade das coisas. Algo que o "dever-ser" pode construir de um modo diverso. É que a norma náo se limita, como dito, às realidades, mas ao que ela diz como deve ser. Assim, pode-se ver uma parede branca e uma determinada norma obrigar a dizer-se que ela é preta. A parede (o "ser") é branca, muito embora a norma (por um motivo qualquer) imponha que ela "deve ser" preta. Na época de Liszt, não era possível se basear nesse dever-ser, pois este estaria sempre sendo comandado pelo ser, que caracteriza o movimento neokantista que reformou o direito penal no 
Com efeito, observemos que essas ideias deram azo a muitas especulaçóes e sugeriram a construção de alguns elementos dogmáticos (SILVA SÁNCHEZ, 1992. p. 56). Foi dele também que se elaborou entre os anos de 1902 e 1909, por ordem de Nieberding (Secretário de Estado e Ministro da Justiça do segundo Reich), uma obra que comparava o direito penal alemáo e o direito penal do resto do mundo, marcado por sua órbita de influência: Vergleichende Darstellung des Deutschen und Ausländischen Strafrechts, em dezesseis tomos (ROXIN, 2014. pp. 14 e ss.). Dessa obra surgiu ainda uma série de propostas de reforma do Código Penal alemão de 1871, que terminou por incorporar as importantes alteraçôes lideradas por Welzel e Roxin.

Não obstante, após a primeira guerra mundial, a primeira dessas propostas se converteu em um projeto apresentado por Radbruch (então Ministro da Justiça na República de Weimar), mas o projeto não seguiu adiante por causa da ascensão de Hitler, o qual fez surgir uma nova proposta, encabeçada pelo mais respeitado penalista da década de 1930: Mezger. Uma sugestão que caiu por terra, com o fim da segunda grande guerra e a redemocratização da Alemanha.

Por fim, por meio do instituto Max Planc, foram retomados os projetos da República de Weimar. E como resultado reformou-se, em 1969, a parte geral do Código Penal alemão de 1871, aproveitando-se tanto as ideias de Liszt como de Welzel. Na verdade, o normativismo ou neokantismo que vivenciou toda essa obra legislativa náo desconstruiu o sistema causalista. O que ocorreu é que foram absorvidas pela doutrina as mudanças propostas pelos neokantistas ou normativistas.

Uma delas era o tema de que a omissão não deveria limitar-se à propriamente dita: a omissão de prestação de socorro. Registre-se que, segundo os mencionados autores do início do século passado, dever-se-ia dar espaço a uma omissão imprópria, assim como a um dolo indireto e a um resultado formal ao delito que anteciparia o momento de percepção da ofensa ao momento de sua prática.

Com efeito, para melhor vislumbrarmos o significado dessas propostas, tomemos como exemplo uma delas: A omissão imprópria. Olhemos o caso de um médico que não

começo do século XX. Figueiredo Dias (2004, pp. 229 e ss.) anota, a respeito: "O chamado sistema neoclássico funda-se essencialmente na filosofia dos valores de origem neokantiana, tal como ela foi desenvolvida, nas primeiras décadas do século XX, pela chamada Escola do Sudoeste Alemão ou Escola de Baden (Windeland, Rickert, Lask). Ela pretende retirar o direito do mundo naturalista do "ser", para, como ciência do espírito, o situar numa zona intermediária entre aquele mundo e o do puro dever-ser, mais rigorosamente num campo referencial, no mundo das referências da realidade aos valores, do ser ao dever-ser e, logo por aí, no mundo da axiologia e dos sentidos. Há por isso, no que toca ao sistema do crime, que preencher os conceitos com estas referências, nomeadamente passando a caracterizar o ilícito como danosidade social e a culpa como censurabilidade do agente por ter agido como agiu, quando podia ter agido de forma diferente. $\mathrm{Na}$ Alemanha, nome cimeiro desta orientação jurídico-penal foi o de Mezger. Na Itália, o de Delitala. Em Portugal foi, sobretudo deste húmus que sempre se nutriu o pensamento de Eduardo Correia”. 
atendeu a um paciente, sob o absurdo argumento de que a pessoa era pobre. Atentemos que o crime de omissão de prestação de socorro está previsto nas mais diversas legislaçóes penais. No Brasil se encontra no art. 135 do Código Penal. A pena para esse crime é de até seis meses de detenção, permitindo, assim, a aplicação de uma pena alternativa.

Ora, certamente ninguém que tomou conhecimento desse fato - de que um médico não atendeu alguém sob o absurdo argumento de ser o paciente pobre - ficará satisfeito quando o juiz condenar esse médico só ao pagamento de uma cesta básica.

Foi a partir dessa insatisfação que a doutrina defendeu a ideia de se tipificar uma omissão diferente para aquelas pessoas (como um médico) que, pelo senso comum e pela lei, tinham o dever de agir. Para essas pessoas não se deveria ver apenas o fato em si - uma conduta omissiva -, mas o dano que foi causado: a morte da vítima.

Como resultado, criou-se uma figura chamada de omissão imprópria (que será vista mais adiante, quando da análise da teoria do crime). Nesse caso, pessoas como o médico em questão, responderiam por homicídio ( $\$ 2^{\circ}$ do art. 13 do Código Penal brasileiro), embora, ao se olhar para a natureza da conduta do médico, vê-se apenas que ele praticou uma omissão, ao não prestar socorro.

Com outras palavras, por ser médico (e ter esse dever de agir), ele responde pelo dano que causou. Nesse caso específico, a norma indica que ele praticou um homicídio e não a mera omissão que os nossos sentidos percebem. Não se enxerga aí o "ser" do que realmente aconteceu, mas um "dever-ser". Aquele indivíduo, por ser um médico, tinha o dever de agir. E é isto que fará com que a sentença transmita a ideia de que, assim julgando, a condenação será mais justa.

Foi com base nesse pensamento que se iniciou essa fase em que se dividiu o campo jurídico penal entre o real verdadeiro e o real construído. Foi, também, a partir dessa linha de raciocínio (já fundado na ideia de que tudo era relativo e que a ciência era um método e não o que empiricamente se demonstrava) que surgiu na seara do direito penal, a figura de Welzel.

Esse outro notável doutrinador partiu para a reconstrução do sistema penal, entendendo que o rigor de Liszt prejudicava a própria lógica do direito penal ${ }^{13}$. Para Welzel, o

13 De acordo com Luís Flávio Gomes (2010, p. 142), Welzel teve como meta inicial e mais importante superar o positivimo jurídico de caráter naturalista de Liszt. Segundo esclarece, foi assim que ele reforçou os posicionamentos defendidos pelos autores neokantianos que marcaram o direito penal no começo do século XX, sem sucesso. De fato, conforme acrescenta, Welzel não superou o ambiente teórico construído por Liszt. O que fez foi táo somente uma ressistematizaçáo do direito penal, realçando o que chamou de estruturas lógico-reais. Essas estruturas eram os elementos dogmáticos até hoje abordados (fato típico, legítima defesa etc.). Welzel terminou por reforçar o pensamento abstrato e o método dedutivo desenvolvido em meados do século XIX. Tal conclusão é acolhida pela doutrina mais forte, destacandose as palavras de Figueiredo Dias (2004, p. 232): "Welzel acabou por desembocar no mais refinado e 
exegeta não deveria se basear em um sistema teórico e dedutivo fundado ou construído tão somente a partir da realidade (WELZEL, 2001, pp. 21 e ss.). Em sua concepção, a culpabilidade seria a parte subjetiva do crime, fundada na culpa e no dolo, mas argumentava que isso era insuficiente como método ${ }^{14}$.

E essa constatação de insuficiência foi à concretização das ideias normativistas no sistema penal. Um ideário que hoje, apesar de longe de estar superado, encontra-se esfumaçado com as posiçóes funcionalistas dispostas por Roxin. Posições que serão discutidas, a partir de agora, mostrando-se em que ponto o normativismo deve ser posto ou visto como uma letra morta no ambiente jurídico-penal.

\section{A Política Criminal na Atualidade: Entre os Valores Oitocentistas e a Con- cepção Contemporânea}

Ora, visto, em um primeiro momento, que o normativismo trouxe benefícios ao sistema penal e que Welzel com a sua reorganização sistêmica conferiu mais força ainda as propostas feitas no começo do século XX, impóe-se abordar em que medida as ideias emergentes podem sacrificar tudo o que até agora foi cimentado.

Repare-se que ao afirmar a importância da expressão cunhada por Liszt de que a dogmática é a barreira intransponível da política criminal (das Strafrecht ist die unübersteigbare Schtranke der Kriminalpolitik), Roxin (2000. pp. 30 e ss.) não deixou passar a oportunidade de salientar que não existe uma oposição entre a política criminal e o pensamento sistemático edificado pelos causalistas.

Ao contrário, Roxin salienta que os instrumentos como, por exemplo: estado de necessidade, erro em direito penal e desistência voluntária são espaços propícios a uma regulação social.

Para Roxin, tais mecanismos antes de se contradizerem compóe uma unidade dialética. No entanto, não mais como uma ideia normativa, que tanto significou para o mundo dos autores acima mencionados, e sim uma ideia político-criminal, fincada nas funções de prevenção ou de custo e benefício para a aplicação da pena. Seria isso, segundo ele, o que deve reger o direito penal.

inflexível conceitualismo, face ao qual pouco resta para a actividade jurídico-política do legislador e para a actividade concretizadora do intérprete e aplicador: tudo residiria e só em determinar as estruturas lógico-materiais ínsitas nos conceitos usados pelo legislador e, a partir delas, deduzir a regulamentação e a solução aplicáveis ao caso”.

14 Para Faria Costa (2000, pp. 143 e ss.), ficar adstrito a descrever o que existe significa infringir as regras que norteiam a hermenêutica, a qual deve se fundar em diferentes cânones. Cite-se, por exemplo, a regra da totalidade "que indica que o círculo hermenêutico parte de um todo, que por seu turno desvela e revela a totalidade em contínuo (...). Tenha-se presente, em primeiro lugar, que as unidades compreensivas não têm, por mor de qualquer lógica interna, de ser absolutamente fechadas”. O sistema expressa ou deve expressar o que a sua própria autonomia, como fenômeno de inteligibilidade, incute-nos. 
Com outras palavras, para Roxin, seria o princípio da insignificância e as mesmas ideias de custo e benefício que justificariam situaçóes de estado de necessidade ou mesmo de se exigir ou não uma conduta diversa de alguém. E aqui vai a nossa indagação, estaria tal sugestão correta?

Com efeito, olhemos que esse raciocínio não passa despercebido à ponderaçôes de doutrinadores como Fábio Roberto D’Avila (2008, pp. 452 e ss.): “A versatilidade que confere Roxin à noção de política criminal implica uma excessiva abertura e, portanto, também, a perda do seu rigor conceitual como critério de orientação na resolução de casos, servindo, muitas vezes, de recurso meramente retórico”.

De fato, deve-se sempre indagar o ponto em que há esse dito benefício. Nem sempre o que é mais útil é o mais justo. E dito isto, pode-se afirmar, ao se deparar com o pensamento funcionalista de Roxin, que este não nos diz de uma maneira suficientemente clara quais são os precisos critérios que irão permitir a mencionada aproximação entre os fins do direito penal e os seus conteúdos sociais.

Aproveitando-se mais uma vez do que fala Fábio D’Avila (2008, pp 452 e ss.): “Se o surgimento do estado de necessidade supralegal é um exemplo de incorporação de valoração político criminal, resta saber qual o limite, se há algum, para o reconhecimento de um valor como critério político-criminal".

Ora, ninguém pode duvidar do significado do contributo de Roxin. Depois dessa inserção normativa que ocorreu no começo do século XX, as suas ideias de inserção político-criminal foram as mais significativas. Com certeza, a expressão "exigência de uma conduta diversa" sintetiza algo que vai muito além do que se exculpa por trás de uma coação moral irresistível ou uma ordem hierárquica superior não manifestamente ilegal.

Assim como também a expressão "estado de necessidade" expressa algo mais amplo do que Welzel fez perceber quando edificou a primeira grande reforma do sistema penal (ROXIN, 2004. pp. 46 e ss.). É fácil admitir que Welzel fechou o sistema quando afirmou que essa última excludente só existe quando alguém ofende determinado bem jurídico em uma situação de perigo que não provocou, tendo de ser esse bem de igual valor ou de valor inferior.

Roxin (apud DIAS, 2004. pp. 562-563) refletiu corretamente quando trouxe a seguinte situação: Em um ônibus, viajam cinco pessoas: o motorista e, como passageiros, dois homens, uma mãe e uma criança. Acontece um acidente. $\mathrm{O}$ ônibus está prestes a cair em um precipício. O motorista morre no choque. Sobrevivem a mãe e o filho, mais os dois adultos. A mãe quebra a saída de emergência. Antes de puxar o filho, ela verifica que terá de optar, pois, ao puxar o filho, o ônibus se precipitará e os dois adultos morrerão. Contudo, caso ela deixe os dois adultos saírem, será o seu filho quem morrerá. 
Ora, suponha-se que a mãe opte por salvar o filho. A rigor, o seu ato será interpretado como um crime, pois, como dito há pouco, Welzel condicionava que, para existir o estado de necessidade, tinha-se de salvar um bem mais valioso: duas vidas valem mais do que uma.

Seguindo essa linha de raciocínio, Roxin indagou: Como exigir uma conduta diversa dessa mãe? Sem dúvida, essa expressão tinha de significar algo mais. O estado de necessidade não poderia ficar adstrito a regras tão fechadas: como a de que um bem só pode ser salvo se for mais valioso que outro.

Contudo, é a saída observar todas as estruturas do sistema finalista pelas funções do próprio direito penal: ${ }^{15}$ Atente-se que para Roxin, dever-se-ia, por exemplo, alterar a culpabilidade, deslocando a exigência de conduta, para um novo requisito denominado por ele de responsabilidade (Verantwortlichkeit). Esta não seria mais excluída simplesmente pela coação ou pela ordem dada por um superior da pessoa que cometeu uma determinada ofensa a um bem jurídico, mas pela adequação da reprimenda às necessidades de prevenção (MAURACH; ZIPF, 1994. p. 538).

De acordo com Roxin essa sua ideia permitiria ver o sistema penal através de uma valoração (fundada nas funçóes do direito penal) que o flexibilizaria, sem traí-lo (FIANDACA; MUSCO, 2006. pp. 05 e ss.). Permitiria também aproximar os dois universos postos tanto por Liszt como pelos neokantistas.

Ora, independentemente de toda a análise que pode ser feita pelo magistrado, este não deveria incriminar as condutas que, em uma relação de custo e benefício (Zveckrationalität), não ofenderiam bens jurídicos, a ponto de fazer enxergar que não será vantajoso o uso do sistema penal (ROXIN, 2002. p. 62; VOLK, 1998, pp. 479 e ss.; CORTESI, 2006, pp. 414 e ss.).

Sim, mas indague-se novamente: Seria saudável delimitar as vertentes axiológicas da culpabilidade ao superficial e restrito universo da prevenção geral e especial? Não esqueçamos que o conceito de culpabilidade é um elemento fundamental e indispensável para o reconhecimento do crime. Vinculá-la a consequência do delito é indiscutivelmente um equívoco metodológico.

Até porque o pressuposto lógico da consequência jurídica é a existência ou não do fato criminoso. Só quando se tem por certo a ocorrência de um crime é que se faz possível cogitar sobre a legitimidade e conveniência político-criminal de lhe atribuir uma determinada sanção.

15 "Sugere Roxin a decidida orientação do sistema do direito penal às valoraçóes da política criminal, de maneira que as principais categorias do sistema penal (tipicidade, antijuridicidade, culpabilidade) seriam redefinidas em função das exigências político-criminais”. (apud GOMES, 2010, pp. 146-147). 
Suprimir-lhe isso, de fato, segundo Fábio D’Avila (2008, pp. 452 e ss.): "é admitir uma noção de crime que deixa de ter conteúdo próprio para assumir, ele mesmo, um contéudo funcionalizado".

Uma política criminal crítica é uma tarefa do Estado de Direito. Todavia, não há como se deixar de reparar o esfumaçamento que a mesma gera nos interesses de preservação de direitos e garantias fundamentais. Tão bem delineados na série de instrumentos edificados pela dogmática ao longo dos últimos dois séculos.

No âmbito funcional, até mesmo o conceito de pessoa pode ser suscetível de correção, no momento em que esse começasse a dificultar a obtenção de fins políticos, preestabelecidos pelo Estado. Mais do que uma crítica, ou um reducionismo a uma lógica de custo e benefício, precisa-se compreender que a normativização do direito penal necessita sempre ser revista. Mas de um modo em que o seu sentido não seja extraído de um relacionamento com a legalidade, mas com a instituição de uma validade que encontra raízes, a margem de dúvidas, em uma compreensão onto-antropológica do direito penal.

Uma compreensão, assim propugnada por Faria Costa (1995, pp 30 e ss.): ver-se a compreensão das regras impostas pela dogmática em um "reconhecimento que estrutura o ser comunitário, opondo-se as elaboraçóes funcionalistas, bem como repondo o ilícito para o centro da proposição normativa e do debate penalístico acerca da validade da leis penais".

\section{Conclusões}

À guisa de consideraçóes finais, registre-se que se faz cada vez mais necessário se travar um embate entre o domínio do efêmero e do transitório. Tudo com o objetivo de prestar informaçóes teoricamente consistentes ao leitor.

Claro que a exemplo de qualquer trabalho que se pretenda científico, esta narrativa é aberta. Está sempre à procura de aperfeiçoamentos ou contributos. Afinal, a complexidade dos temas abordados não admite a soberba intelectual.

No entanto, apesar das suas limitaçóes, buscou-se sustentar um ponto: o de que qualquer mudança ou proposta de alteração deve ambicionar uma consistência mínima, tão necessária nestes tempos em que a dogmática vem sofrendo fortes crises.

É cada vez mais difícil se entender os instrumentos teóricos edificados pelos cultores da ciência penal como elementos de percepção de um crime.

Diante dos ruídos da incompreensão e dos preconceitos de quem se limita a enxergar partes de jurisprudências, esses instrumentos vêm sendo objetos de conclusóes que atingem a própria condição humana, tão carente de segurança e estabilidade. 


\section{Referências}

BRANDÃO, Cláudio. Teoria jurídica do crime. Rio de Janeiro: Forense, 2001.

CORTESI, Maria Francesca. "Le disposizioni in tema di nisure di prevenzione". DPP. 4. Milano: IPSOA, 2006.

COSTA, José Francisco de Faria. O perigo em direito penal. Coimbra. Coimbra editora, 1995.

D’AVILA, Fabio Roberto: Os limites normativos da política criminal. Berlim. ZIZ, 2008.

DIAS, Jorge de Figueiredo. Direito penal. Parte geral. Tomo I. Coimbra: Coimbra editora, 2004.

FIANDACA, Giovanni; MUSCO, Enzo. Diritto penale. Parte generale. Quarta edizione. Bologna: Zanichelli Editore, 2006.

FRANK, Reinhard. Sobre la estrutura del concepto de culpabilidade. Buenos AiresMontevideo. IbdeF, 2004.

FREITAS, Ricardo de Brito A. P. As razóes do positivismo penal no Brasil. Rio de Janeiro: Lumen Juris, 2002.

GOMES, Luís Flávio. Direito penal. V. 1. São Paulo: Revista dos Tribunais, 2010.

ROXIN, Claus. Novos estudos de direito penal. São Paulo: Marcial Pons, 2014.

Funcionalismo e imputação objetiva no direito penal (Tradução de Luís Greco. Análise dos $\$ \$ 7$ e 11 da 3 ed. de sua obra Strafrecht, Allgemeiner Teil). São Paulo: Renovar, 2002.

. Política criminal e sistema jurídico-penal (Tradução de Luís Greco. Sem referência ao título original). São Paulo: Renovar, 2000.

TAVARES, Juarez. Teoria do injusto penal. Belo Horizonte: Del Rey, 2000.

Direito penal da negligência. 2 ed. revista. Rio de Janeiro: Lumen Juris, 2003.

SILVA SÁNCHEZ, Jesús Maria. Aproximación al derecho penal contemporáneo. Barcelona: Bosch, 1992.

VOLK, Klaus. “Diritto penale ed economia”. RDPEC. Milão: CEDAM. 1998.

WELZEL, Hans. O novo sistema jurídico-penal (Tradução de Luiz Regis Prado. Sem referência ao título original). São Paulo: Revista dos Tribunais, 2001.

ZAFFARONI, Eugenio Raul; PIERANGELI, José Henrique. Manual de direito penal. Parte geral. 2 ed. São Paulo: Revista dos Tribunais, 1999. 